\title{
Educational Networking Site: A Case of Polytechnic of Namibia
}

\author{
Lucia Fortune Mukanya $^{1}$ and Shawulu Hunira Nggada ${ }^{2}$ \\ ${ }^{1,2}$ Department of Computer Science, \\ Faculty of Computing and Informatics, \\ Namibia University of Science and Technology, \\ 13 Storch Street, Windhoek, \\ Namibia \\ ${ }^{1}$ mukanyal@gmail.com, ${ }^{2}$ snggada@nust.na
}

\begin{abstract}
The 21 st century is characterised by the advent of Social Networking Sites, designed to enable social activities over the internet. Social Networking has changed the way people interact; messaging, chatting, photo sharing, reunion with old friends or colleagues, meeting new people living in different countries, etc, all at the touch of a button. Social Networks also make the formation of a group possible which is a site dedicated to a particular type of conversation or designed to allow communication among people with similar interest. To this regard, Social Networking Sites (SNS) dedicated to students emerged and was termed Educational Networking Site (ENS). The ENS provides a platform where students could interact among themselves and with lecturers. This work investigates E-Portsocial; the ENS of the Polytechnic of Namibia (now Namibia University of Science and Technology). The investigation is focused on the factors to consider if an educational institution would build an effective and successful ENS in terms of meeting the expectations of both the organisation and its users. The study also investigates how an Educational Network could be improved in terms of its set up, to ensure availability with minimal threat to security.
\end{abstract}

Keywords: Social network, educational network, E-Portsocial

\section{Introduction}

The advent of Social Networking Sites (SNS) has changed the way people interact, work and play. SNS are meant to enhance communication in already existing social networks and, or meeting new people over the internet with similar interest. CalvoArmengol, Patacchini and Zenou [1] explained the term homophily as the principle that a contact between similar people occurs at a higher rate than among dissimilar people, and when applied to SNS, it is only people who have interest in the topic or discussion at hand that join in the conversation or the group. A site that is dedicated to use by students, lecturers and all individuals in a given Educational Institution is called Educational Networking Site (ENS). Thus, it is expected that any form of communication on the site should revolve around Education [2].

Educational Networking Sites (ENSs) are designed to meet the need of a particular Educational Institution by providing communication outside and inside the classroom. ENS provides a good platform for learning to continue outside the classroom. Studentlecturer communication can be done anywhere at any time, be it via audio, video; e.g., instant messaging, voice over Internet protocol, etc., This allows one lecture to teach a lot more students. In the traditional class delivery, it may be necessary to have a large venue to enable the use of a single lecturer for the class delivery. The communication under such approach is likely to be one way as the lecture only talks and receives little or no feedback from the class. However, if the class communicates over an ENS, the lecturer can receive 
feedback during or after the class session. The use of ENS would improve communication and students' understanding. It may also be a platform for students who are shy in the class to voice their contributions, questions or comments during the lesson. The use of an ENS will allow them to post these during or after the lesson and hence, be of greater help to them.

In certain programme or course offer modes such as distance and part-time, classmates hardly or never meet. This is a disadvantage to team building, team work and collaboration among classmates. ENS provides a platform for classmates to meet and discuss issues at the time that is convenient for them. There could be several categories of students within a given institution, for instance some students may be in a full-time employment and hence, may not have time to physically meet the lecturer. The use of ENS provides a platform where such students could easily communicate with the lecturer online. Additionally, a problem and its solution could be posted such that students who have similar problem would basically refer to the posted solution.

The needs for any institution differ depending on the nature and calibre of students being catered for, the type of data to be processed on the platform, the resources available, the availability of software and hardware, and the frequency of monitoring, evaluation and implementation of updates on the platform. A platform designed to cater for medical students for example would be expected to be able to upload images, word documents and videos, on the other hand, a site designed to cater for medical professors would require instant messaging as one of the features. In an institution that has both students and lecturers on the same site and several schools (or faculties) which offer various programmes, there may be a number of functions required to benefit both the students and lecturers. To extend the width of collaboration, the services of ENS could be extended to alumni community.

\section{Social Networking Technology}

Typically, the technologies used in SNS are also used in ENS. SNS technologies have become a branding tool for organisations; this is because it is a platform that would also portray the image of the organisation. Hence, organisations should have their business case in mind when adopting social networking technologies [3]. Institutions have then taken it upon themselves to build their own ENS to suit their needs instead of adopting an existing SNS. Basically, ENSs are built using the Social Networking technologies that also include features such as scalability, and security features such as privacy, confidentiality, integrity, authentication, non-repudiation, availability and accountability [4]. Additional features may depend on the set-up, the needs and available resources.

Most Social Networking platforms use open source sever technologies, for example the operating system behind Twitter, LinkedIn and MySpace are all Linux based. Facebook uses F5 Big-IP, which is a family of Linux-based appliances that also perform network management [5]. As for web servers, Apache is the Web server of choice and LinkedIn uses Sun ONE Web Servers in addition to Apache. Most of the social networks also use Sun Microsystems' MySQL database management system to organise their users' messages and status update [5]. The main reason for using open source technologies is because technology has always been about collaboration and continuous improvement [6].

There are currently various open source Social Networking technologies available. The main difference between the platforms is the licensing, compatibility with plug-ins and features offered.

\subsection{Features of Social Networking Technologies}

Some of the popular Social Networking technologies in educational environments include Ning and Mahara; these two are discussed next. 
2.1.1. Ning: Ning came into existence in 2005 as a platform that was designed to allow individuals and organisations to design their own custom SNS. Ning offers customers with the ability to create a community website with a customised appearance and feel. Ning Networks currently include community features, publishing tools, social integration, smartphone and tablet ready, custom design and URL, privacy and moderation control [7]. The community features include forum, photo liking and sharing, unlimited subgroups, customised member profile, member categories and email broadcast capabilities. The publishing tools include the advance blog feature, Search Engine Optimised (SEO), ability to add multiple blogs and invite other experts or members to co-publish and unlimited custom HTML page. Social Integration includes the ability for members to sign in via Facebook, Twitter, LinkedIn or Google, seamless sharing to social media sites, integrate Youtube and Vimoe videos on social channel activity feed. Smartphone and Tablet ready feature is enabled by the responsive design utilising HTML 5.

Ning was an open source platform for the hosting of social applications at its inception [8]. This means that the source code was available for the users to fork and modify it to meet their specific needs. The company re-organised into profit making and started off by reducing the programmer's ability to modify the source code. However, Ning does allow developers to have some source level control of their social networks, enabling them to change features and underlying logic.

The social networks running on Ning's service are programmed in PHP while the platform itself is built in Java [9]. Developers can customise and change the appearance of their Ning Networks by launching the Ning Design Studio which allows users to choose from pre-made templates, varying in colour, font, background and foreground images and layout design [10].

2.1.2. Mahara: One of platforms common to higher institutions is the Mahara Content Management System (MMS). MMS operates under GNU Public Licence version 3 or any other later version. It is designed to provide the tools to create and maintain a digital portfolio of learning, social networking features and to allow users to interact with each other. MMS provides users with blogs, a resume builder, file management and a view creator which is a tool to help users organise contents in a particular way for others to see. MMS also features interoperability with the Moodle Learning Management System [11]. MMS supports the Leap2A specification for importing and exporting data, allowing a user to take their content with them from one MMS installation and import it into another. There is limited interoperability between MMS and other systems which support the Leap2A standard [11].

\subsection{Social Networking Licensing}

Many people are of the opinion that all open-source licences are free and hence they can modify and redistribute it at no cost or restriction. In software development, there are authors who place their codes in public domain which is a way of wavering an author's copyright, hence, no licence is required to modify or redistribute such software. Most open source software come with free licence which is known as 'copyleft' [12] that allows the source code to be modified and usually carries no restrictions. Sometimes the licensing comes with restrictions such as the source code should be made available even after modifying it, which means it takes away the 'copyrights' from whoever modified it.

The other form of open source licencing is one that allows the making of 'while label' products on the market [13]. This is where marketers are allowed to brand software as their own and distribute it as such. In this case, it means the modified source code is no longer available to the end user.

\section{Namibia University of Science and Technology}


The Polytechnic of Namibia (PoN) officially became the Namibia University of Science and Technology (NUST) as announced by the Honourable Minister of Higher Education, Training and Innovation, Dr Itah Kandjii-Murangi, by Notice in the Government Gazette of 16 November 2015 [19]. A larger proportion of this work was carried out during the PoN era but remains applicable. The PoN was established to assist in the development of Namibia by providing tertiary technological career-oriented education at international standard. Its objective is the practice, promotion, and transfer of technology to meet the professional human resource requirements of Namibia and those of the region and beyond [14]. The PoN, through its Distance Education Centre under the Office of the Registrar, aims to make education more accessible to Namibians through distance education [15]. The PoN's Business Computing Department (now Department of Informatics) in 2010 launched Postgraduate Certificate Programmes in its effort to produce graduates that are equipped with the most appropriate knowledge and skills that are beneficial to the development of the country.

To cater for students and lecturers of the institution, the PoN created a centre for support called Centre for Teaching and learning (CTL) whose vision is to enhance the teaching and learning competencies of faculties and students through the use of innovative methodologies and technologies that ensure success for all. The objectives of the centre are among others to develop and maintain professional development programmes for faculties that promote teaching and learning practices; provide advice on curriculum development and related matters and to promote the use of technology in teaching and learning [16]. The CTL being charged with such mandate developed various platforms to enhance teaching and learning at the institution. Their first attempt was to develop e-learning platforms and increased use of e-learning components across the curriculum to promote student familiarity with technology and help manage courses delivery in different ways. These e-learning components are part of classroom-based classes, hybrid classes, or fully on-line courses.

In 2013, the CTL developed an Educational Networking Site initially named Education for Sustainable Development. This site is a fully featured electronic portfolio system with features for networking to create online learning communities. This space allows students, lecturers and experts in different domains to share resources, collaborate on projects, communicate ideas and form study groups to enhance learning using technologies. Students can use this space to plan for their projects and learning, write curriculum vitae and share documents with selected people. This system can also be used as an assessment tool; especially to create and assess electronic portfolios [16]

The PoN's SNS is expected to cater for more than 15,000 users. The site is meant to provide students with a platform to communicate and to store documents so that less paper is carried around. As of May 2013, students especially the part-time and distance who are supposed to benefit from the site were aware of the existence of the site but did not know how to access it.

In a study conducted at the PoN in May 2013, it was found that regarding the Educational Networking Site which was previously named Education for Sustainable Development now renamed E-Portsocial, out of the 338 students surveyed, only 14 had heard of E-Portsocial, and even fewer had used it [17]. A social network's effectiveness depends on the size of its users, and currently, not enough students know about EPortsocial in order to attain the huge size of users that would popularise its use [17]. The most common hindrances to using PoN's E-Portsocial are Internet-related; specifically many dead zones around campus and limited bandwidth especially on the student network [17]. Some setbacks could be understood through the diffusion of innovations (DOI). DOI is a theory of how, why and what rate of new ideas and technology spread through cultures [18].

When the E-Portsocial was launched in 2012 it was advertised on the PoN students' site in one of the corners. There was no other way the students got to know about it 
besides word of mouth. There was no marketing strategy in place and up to date (2014) very few lecturers have heard about it. For those who might have somehow come across the site, there is nothing on it that links to the PoN. The ICT policy at PoN does not accommodate the platform hence, it remains a white elephant. The design of the site cost PoN man hours, resources and money, and if this site remains unutilised then the project could be seen as a waste. The PoN's policies are such that Social Networks are not accessible during working hours, thus, they are available during lunch time and after 4:30pm. This policy hinders the use of the Educational Network as it is affected by the same policy. Hence, when access to Social Networks is granted, most students would rather go to networks were they can meet their friends.

The challenges faced by the PoN's E-Portsocial are exactly the motivation for developing a framework on how successful ENS' could be setup. This implies that the framework could help improve the E-Portsocial of PoN and it is discussed next.

\section{Framework to Improving Educational Networking Site}

In order to establish the framework, a study was conducted on other institutions in Namibia which use ENS. The institutions include Windhoek International School and University of Namibia (UNAM) - Khomasdal Campus. The study found that successful projects are designed based on a framework. A framework is a real or conceptual structure that serves as a support or guide for building a thing. In the development of an ENS and E-portfolio, it is important to have a laid down format of what steps will be followed and if necessary to have a team to work on different aspects of the development. The framework addresses identified aspects of development and it is as follows.

\subsection{Hardware and Software}

The current hardware and software might need to be adjusted to meet the growing needs and demands of the network.

- How will the Educational Network and E-portfolio systems impact software systems, such as the institution's current records management system, student information system and databases?

- How many and what kind of servers are necessary to hold increasing number of storage information? What will be needed to maintain and back up servers?

- What plugins and tools, file formats and browsers are required depending on the platform the Educational Network or E-portfolio is built?

- With what technologies can an offline, portable portfolio be implemented for authors to take with them (examples are XML and content packaging)?

- Does the storage space allow the students to keep lifelong records?

- Will the institution acquire custom made packages or will they get open source platform and develop according to their needs?

- Can the bandwidth accommodate the introduction of the Educational Network and E-portfolio? What can be done to minimise the impact on the bandwidth?

- What are the potential security threats to the system by the introduction of the ENS and E-portfolio? How can they be addressed?

- What are the standards that are key in ensuring that systems meet user expectations for portability and adaptability?

\subsection{Support and Scalability}


The plan of an Educational Network should include the plan to grow; that is what will be done when the network grows.

- Can the Educational Network and E-portfolio scale adequately as its usage grows and storage expands?

- Is there adequate staff to develop, deploy and maintain the system?

- Is there infrastructure in place to properly train students, faculties and administrators on how to use the Educational Network and the E-portfolio system?

- Does the Network Policies of the institution accommodate the Educational Network and E-portfolio? If not, how can it be addressed?

\subsection{Security and Privacy}

- What are the legal regulations regarding the use of ENS and E-portfolios in the country?

- What policies need to be in place for governing information access, security and privacy? How will it be managed?

\subsection{Ownership and Intellectual Property}

- The legal aspect of who owns the information that has been generated on the Educational Network should be catered for in the implementation plan.

- How does the system authenticate users?

- Who is the real owner of the documents in any Educational Network or E-portfolio?

- What can and cannot be posted in an Educational Network or E-portfolio? How is this monitored?

- Who owns the record? Can it be transferred to another institution?

- Can a user still access the information if they no longer have affiliation to the institution?

- For how long will the record be kept after a student has finished with his or her studies?

\subsection{Assessment}

- What kind of assessment will the Educational Network and E-portfolio system support? What standards will be incorporated into the assessments?

- How will assessment data be maintained and archived, and for how long?

- How can student assessment be used to assess the programmes for which they enrol? How might this affect the assessment of the institution?

\subsection{Adoption}

The adoption plan should be in place before the implementation of the Educational Network.

- What does the administrator expect?

- What do lecturers expect?

- What do students expect?

- How will the idea be marketed to them? 
- Is the system user-friendly enough for easy adoption?

\subsection{Long-Term Maintenance}

There should be a plan in place for how the Educational Network will be maintained and monitored

- How will information be maintained over time?

- What policies are needed for deleting user accounts?

- How will the long-term storage requirements be managed?

\section{Conclusions}

Educational networks by their very nature are flexible, borderless, and innovative; they are able to create collaborative environments and develop agendas that grow and change with their participants. As technology transforms the institutions of society, changing the way people work, communicate, and learn, educational institutions must accommodate and adapt to these new conditions. Unfortunately, some institutions by their policies have difficulties in making changes that would suite contemporary trends in Educational Networks. To address some of the challenges or difficulties, this paper developed a framework that could be used in improving Educational Networking Sites.

\section{Acknowledgements}

The study was made possible by the cooperation and assistance of the Centre of Teaching and Learning at the Namibia University of Science and Technology, in particular our appreciation goes to Mr Joseph Gandanhamo and Mr Maurice Nkusi. We also acknowledge the support from Windhoek International School, Namibia with special thanks to the Network Manager, Mr J. Peree and ICT teacher, Mr Maramba. Finally, we acknowledge the support from University of Namibia, Khomasdal Campus with special thanks to the Network Manager, Mr Ikanjo.

\section{References}

[1] A. Calvo-Armengol, E. Patacchini and Y. Y. Zenou, "Peer effects and social networks in education", St Louis: Reserve Bank of St Lois, (2007).

[2] S. Hargadon, "Educational Networking: The important role Web 2.0 will play in education", Teaching and Learning in a Networked World, vol. 3,no. 70, (2009).

[3] A. Martin, and R. R. Van Bavel, "Assessing the Benefits of Social Networks for Organisations", Seville: European Union, (2013).

[4] L. Peterson and B. Davie, "Computer Networks: A System Approach", San Franscico: Morgan kafmann Publisher, (2003)

[5] S. Weber, "The Success of Open Source", Harvard: Harvard University Press, (2003).

[6] G. Kasper, "A framework for thinking about innovation in philatrophy", In W. Foundation, Intentional Innovation: How getting more systematic about innovation could imrove philantropy. Washington DC: MonitorInstitute, vol. 3, (2008), pp. 28

[7] G. Casey and T. Evans, "Design for learning:online social network as a classroom environment",The international review of research in open and distance learning, vol. 2, no. 89, (2011).

[8] M. LaMonica, "Andreessen adds some Ning to the Web", CNET News, vol. 2, no. 20, (2005).

[9] S. Shankland, "Andreesson: PHP succeding where Java isn't", CNET, vol. 2, no. 21, (2005).

[10] N. Burr, "Ning Design Studio and Instant Ad Basic", Ning, (2010).

[11] P. Gerbic, P and M. Maher, "Collaborative self-study supporting new technology: The Mahara eportfolio project”, ASCILITE 2008 Melborne. Melborne: Auckland university of Technology, vol. 2, no. 321, (2008).

[12] M. Brydon and A. Vining, "Adoption, improvement and disruption: prdeicting the impact of open source in enterprise software market", Jounal for database management, vol. 3,no. 94, (2008).

[13] L. van der Pool, "There is a new appetite for peddlers of cheap eats", Boston Business Journal, (2009).

[14] Namibia Business Innovation Centre, Namibian Partners. Polytechnic of Namibia Annual Report, vol. 13, (2011), pp. 45.

[15] C. Keyter, "Polytechnic of Namibia Distance Education Centre. Southern Africa Global Distance education", (1999). 
[16] Centre of Teaching and Learning. CTL PoN. Annual report, vol. 1, no. 4, (2013).

[17] L. F Mukanya, E. Mercer, E. P. Sylvia, S. Peter and H. Sputzke, "Awarenes and education of ELearning", Mercesussus: Worcester University Institute, (2013).

[18] O. Folorunso, R. Vincent, A. Adekoya and A. Ogunde, "Diffusion of Innovation in Social Networking Sites among University Students", Interantional Journal of Computer Science and Security, (2013).

[19] Namibia University of Science and Technology, Poly Now Officially a University [online], Available: http://www.nust.na/?q=news/poly-now-officially-university, November 20 (2015), [Accessed 09 December, 2016].

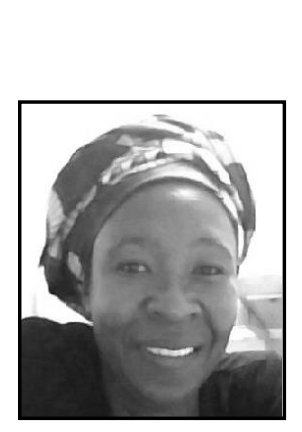

\section{Authors}

Lucia Fortune Mukanya, holds Masters in Information Technology from the Polytechnic of Namibia, BSc Mathematics and Statistics (Honours) and Diploma in Education both from University of Zimbabwe. She holds an International Computer Driving Licence from the Computer Society of Zimbabwe, and Interconnecting Cisco Network Devices - Cisco certification 1.

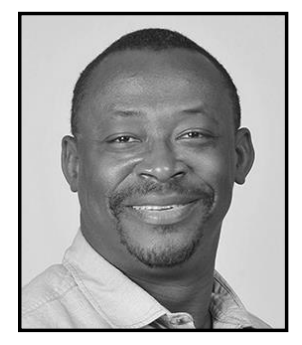

Shawulu Hunira Nggada, has $\mathrm{PhD}$ in Computer Science and PGDip in Research Training both from University of Hull - UK, MSc Software Engineering from University of Bradford - UK and B. Tech (Hons) in Computer Science from Abubakar Tafawa Balewa University, Nigeria. He has Chartered IT Professional membership of BCS The Chartered Institute for IT, Chartered Engineer membership of Engineering Council -UK. He is a Senior Member of IEEE and a member of ACM. He is currently a Deputy Director in Computer Science at Namibia University of Science and Technology (formerly Polytechnic of Namibia). 